\title{
A ARTE ERÓTICA, A FANTASIA E O DESEJO SEXUAL.
}

\author{
Maria do Amparo Rocha Caridade ${ }^{1}$ \\ THE EROTIC ART, FANTASY AND SEXUAL DESIRE
}

\begin{abstract}
Resumo: O sujeito amoroso vive a sexualidade no real de seu corpo e para além dele. $\mathrm{Na}$ busca amorosa sexual que faz, ele depara-se com dimensões outras que integram sua experiência humana e sexual: as normas da cultura, o simbólico da linguagem, a sedução, a fantasia, o olhar do outro. Na vivência do prazer, a arte erótica, a fantasia, a sedução o desejo têm lugar central. Nesse movimento de encontrar e partilhar a sexualidade com alguém reafirma-se o quanto se necessita das referências simbólicas que possibilitam transportar nossa experiência para além do real do corpo que somos. A cultura normatiza as vivências sexuais, mas também cria condições mais encantadas e fantasiosas aos apelos do desejo humano.
\end{abstract}

Palavras-chave: Sexualidade. Arte erotica. Fantasia. Sedução. Desejo.

\begin{abstract}
The lover person lives the sexuality within the reality of his/her own body and also beyond this boundary. Seeking the sexual love, he/she faces other dimensions that are added to his/her sexual and human experience: the cultural rules, the symbolism of the language, the seduction, the fantasy, the others look. In living the pleasure, the erotic art, the fantasy, the seduction, the desire, play the central role. In the movement of finding and sharing the sexuality with someone, the necessity for symbolic references that expand our experience to outside the boundaries of our limited body is enhanced. The culture establishes norms to the sexual experiences, but also creates more fantasy and fairy conditions to the human desire appeal.
\end{abstract}

Keywords: Sexuality. Erotic art. Fantasy. Seduction. Desire.

\section{Da arte erótica}

A vida em nós procede da suposta amorosidade entre dois seres humanos, o que é um belo começo. Somos síntese, fruto da partilha amorosa de seres que se atraem, se juntam e se desdobram noutro ser. Mitologicamente falando, seríamos filhos de Eros, o deus grego do amor, da afrodisia, que, nos tempos primitivos, era considerada um dos grandes princípios do universo. Eros representava a força poderosa que faria todos os seres se atraírem uns pelos outros e por ele nasceriam e se perpetuariam as raças.

Segundo a Mitologia, Vênus, mãe de Eros, preocupava-se, porque ele não crescia. Como permanecia menino, ela perguntou a Têmis a razão disso. O menino respondeu Têmis só cresceria quando tivesse uma companhia que o amasse. Vênus, então, deu ao filho por amigo

\footnotetext{
- Artigo publicado na Revista Brasileira de Sexualidade Humana, 18(1), 2007, p. 179-89. São Paulo: Iglu, 2007.

${ }^{1}$ Psicóloga Clínica, Mestre em Antropologia. Prof ${ }^{a}$. Adjunta da UNICAP - Recife, PE.
} 
Anteros e observou que, quando eles ficavam juntos, Eros crescia, mas voltava a ser menino depois que Anteros o deixava. O mito faz essa narrativa e conclui: É uma alegoria cujo sentido é que o afeto necessita de ser correspondido para desenvolver-se (MÉNARD, 1991, p. $10)$.

Um dos sentidos do termo erótico provém de Eros, esse deus grego do amor, que só cresce quando o afeto é correspondido. O erótico não se confunde com o amoroso, embora ambos tenham por tema comum o amor. Mas, qual o sentido da erótica? O que ela acresce ao sexual? Possibilita, de certo, deter a velocidade do tempo para que não se apaguem os laços, os traços do já vivido, pois o instante de prazer é muito fugaz.

Visto nessa ótica de deter a velocidade do prazer final, a fim de não consumi-lo rapidamente pelo contrário, degustá-lo o termo erótico nos remete a uma nova forma de compreensão. $\mathrm{O}$ termo aloja-se na cultura, como algo da ordem do revelado, do mostrado, do exposto, do realizável imediatamente. Mas o mito de Eros destaca a idéia de que o amor cresce em companhia, em troca, ou cumplicidade. Razão por que, o erótico é algo que acontece entre duas pessoas, quer em breve passagem, em relação demorada, mas em troca cúmplice e velada. No entre duas pessoas é que o erótico se manifesta vertente, de certo modo, silenciosa, discreta, inquieta e atuante. Por que falamos de arte e erótica? Porque o sexo simplesmente não nos basta, e não nos basta porque somos o real do corpo, mas também o mais além dele, ou seja, linguagem e cultura. A sexualidade está nesse entrelace: do real do corpo, do simbólico da linguagem e do imaginário da cultura.

A erótica é uma dimensão da experiência sexual que supõe estética e ela se manifesta pela palavra, olhar, arte, mistério, gesto, risco, beleza, esperteza.

Estudando a imaginação erótica, Stoller (1998, p. 60) se diz esteta e descreve assim a construção da excitação erótica:

[...] é toda ela tão sutil, complexa, inspirada, profunda, fluida, fascinante, aterradora, problemática, imersa no inconsciente e assombrada pelo gênio quanto a criação de sonhos ou arte. A excitação daí procedente é vista como uma tensão dinâmica, que ainda não é prazer, satisfação, um final, uma resolução, mas sim antecipação, uma provocação, uma miríade de possibilidades (idem, p. 66).

Estética e erotismo constituem criações cujo propósito é embaçar ou evitar a realidade simulando algum aspecto da realidade, inclusive a realidade psíquica, tal como as emoções (STOLLER 1998, p. 67) A excitação é um tatear, é incerteza, é percursso. Por isso, simulação torna-se aqui palavra crucial, porque Realidade demais é exatamente demais (idem, p. 67). 
Quando podemos controlar essa dosagem, fazer o roteiro, dirigir a representação, o campo da excitação fica preparado. Para a maioria de nós, a realidade sem adornos seria muito agressiva. Somente uma aproximação com rodeios é possível "[...] os devaneios funcionam no sentido de alterar a realidade" (idem, p. 73). Tais rodeios podem ser fonte de arte, porque a estética aí funciona também como um jogo. Existem poucas verdades eternas na arte ou no erotismo, pois tudo depende da interpretação de certo modo, é uma questão de opinião. Mas, tal qual um enredo de peça teatral, cada detalhe conta.

Georges Bataille (1987) fala do erotismo como atividade diferencialmente humana um fato de cultura, portanto que não se preocupa apenas com o prazer em si e também não faz parte da experiência animal. $\mathrm{O}$ autor chama a atenção para o fato de que curiosamente se estimula bastante o prazer não na liberdade de persegui-lo, mas no interdito de fazê-lo. Ele lembra que o interdito sempre andou de mãos dadas com a transgressão é o conhecido gosto do proibido. É esse interdito que cria o desejo e constitui também a essência do erotismo.

Segundo o mesmo autor, o erotismo está presente tanto nos corpos quanto nos corações e até no sagrado.

[...] O erotismo dos corpos tem algo de pesado, de sinistro... O erotismo dos corações é mais livre, Ele se separa na aparência, da materialidade do erotismo dos corpos, mas dele procede, não passando, com freqüência, de um seu aspecto estabilizado pela afeição recíproca dos amantes (BATAILLE, 1987, p.18)

Como se define o erotismo pelo secreto, ele não pode ser público e talvez gere certa solidão. "A experiência erótica se situa fora da vida ordinária" (idem p. 234), e produz em nós emoção muito intensa. "Talvez seja vizinha da santidade” (idem, p. 235), explica ele. Um exemplo por ele citado são os arroubos místicos descritos por Santa Tereza DÁvila os quais são de grande riqueza erótica, mas neles predominam as metáforas:

[...] Eu vi então que ele tinha uma longa lança de ouro, cuja ponta parecia de fogo e senti como se ele a enterrasse várias vezes em meu coração, transpassandoa até minhas entranhas. Quando a retirava, parecia também arrancá-las e me deixava esbraseada do grande amor de Deus. A dor era tão grande que me fazia gemer e, no entanto a doçura dessa dor excessiva era tal que eu não podia querer livrar-me dela. (BATAILLE, 1987, p. 210).

Essa descrição exprime uma experiência em tudo semelhante a uma relação sexual muito prazerosa. As imagens da longa lança de ouro da ponta que parecia fogo, como se ela entrasse várias vezes em mim transpassando até minhas entranhas são metáforas de todo o gestual de uma intensa relação sexual. Quem pode negar o ardor desse prazer? Contudo há pensadores que concebem esses tipos de experiências místicas como sexualidade transferida, logo, conduta neurótica. De fato, a incapacidade de experienciar isso no real do corpo e no ser que 
se é, talvez indique uma inadequação que convém levar em conta em termos da busca de ser feliz sexualmente.

O corpo sexual é atravessado pelo simbólico da linguagem, o que nos possibilita subverter a ordem estabelecida pelo biológico, adiar a satisfação, deter o tempo, ruminar, saborear, dar sentido ao vivido. A linguagem entranhada no corpo, instaura um debate silencioso de desejos disfarçadamente encantados. "Nessa intenção sempre adiada, brota o desejo" acredita Chalhub (1993, p.17). A imaginação produz esse efeito. Uma fluência verbal produz- se no silêncio e nele pode acontecer a fisgada do desejo. Também segundo Octávio Paz (1994, p. 12), a imaginação move o ato erótico e o poético: " [...] a poesia erotiza a linguagem $e o$ mundo porque ela própria, em seu modo de operação, já é erotismo."

No ser humano, nada determina que a sexualidade seja apenas ação do corpo. No entrelace do corpo, com a linguagem e a cultura, descobre-se a dimensão lúdica, a vontade de prazer; aí já não precisamos transar apenas para procriar, mas também para viver o prazer, encontrar alguém, amar, brincar a vida. $\mathrm{O}$ erótico se situa na vertente do incerto, do silencioso, do brincante e até do misterioso. O outro é imprevisível, difícil de apreender, de segurar, de conter, mas atrai exatamente onde nos escapa.

A alma é erótica, no entender de Adélia Prado (1991, p. 201), mas ela queixa-se quando isso lhe escapa: "De vez em quando Deus me tira a poesia. Olho pedra, vejo pedra mesmo..." Pelo exposto, o corpo do desejo não é tão óbvio assim: é lugar de deciframentos, porque o erótico tem alma, tem mistério.

"O homem é o único ser vivo que não dispõe de uma regulação fisiológica e automática de sua sexualidade”, confirma Octávio Paz (1994, p. 16). Qualquer aderência ao real do corpo como única forma de viver a sexualidade nos faria perdidos de nossas potencialidades eróticas.

Buscamos fora um objeto para o desejo, mas esse objeto nos atrai na medida em que responde à interioridade do desejo. Quando escolhemos o objeto, entra em jogo com freqüência, um aspecto indizível, não uma qualidade objetiva daquela pessoa, que talvez não tivesse, se ela não nos tocasse o ser interior, nada que nos forçasse a escolhê-la especialmente. A escolha humana difere da do animal: ela apela para essa mobilidade interior, infinitamente complexa, que é típica do homem diz Bataille (1987, p. 27). Nesse contexto, o erotismo nos causa certo transtorno, porque coloca nosso ser em questão. $\mathrm{O}$ animal também vive desequilíbrio diante do sexo, mas ele não sabe disso, porque não se põe em questão. Nele nada acontece que se 
assemelhe a uma interrogação. Bataille estabelece a diferença:

[...] se o erotismo é a atividade sexual dos homens, o é na medida em que ela difere da dos animais. A atividade sexual dos homens não é necessariamente erótica. Ela o é sempre que não for rudimentar, que não for simplesmente animal. (BATAILLE, 1987, P. 28)

Embora o erotismo comece onde termina o animal, não há dúvida de que a animalidade continua sendo seu fundamento. A sexualidade física está, de certo modo, para o erotismo assim como o cérebro está para o pensamento: a fisiologia permanece o fundamento objetivo do pensamento. Nessa metáfora, o erotismo é um desequilíbrio em que o próprio ser se põe, conscientemente, em questão. Ao questionar o sujeito se perde: perda voluntária, flagrante, desconcertante, ninguém pode duvidar do que lhe aconteceu. $O$ erotismo tornou-o perdidamente tocado, escancaradamente atingido, visivelmente fulminado, impactado, fora da normalidade de seu viver.

Só os homens fizeram de sua atividade sexual uma atividade erótica. $\mathrm{O}$ erotismo leva o ser humano, ao mesmo tempo, a ser social e humano, humano e animal, além de si mesmo. $\mathrm{O}$ erótico reduzido à visão em que prevalece a explicitação constitui a base da liberação. Mas é a libertação quem abre caminho para a percepção do sentido do erotismo. Por vezes, confundese o erótico com o pornográfico, porém a diferença está em que, enquanto o erótico se expande na criatividade, o pornográfico se esvazia em si mesmo, na mostra repetitiva. $\mathrm{O}$ fato erótico é sutil, complexo, de certo modo misterioso; induz a caminhos desconhecidos, novos, fascinantes e assustadores. Essa dimensão está no homem, na interação de sua humanidade com sua animalidade.

Do erotismo, Bataille avança pela Filosofia e diz:

[...] somos essa abertura a todo possível, essa espera que nenhuma satisfação material acalmará e que o jogo da linguagem não saberia iludir! Estamos à pro- cura de um ponto culminante ... a humanidade toda aspira a esse ponto, que só ela o define, que só ela justifica e lhe dá sentido. (BATAILLE, 1987, p. 253)

Por fim convém lembrar não falamos de experiência interior e do erotismo enquanto cientistas. Fazemos isso do lugar de seres pensantes, encantados e desejantes que somos. Portanto esta escrita não é científica, nem pretende sê-lo. Ela requer comunhão do leitor, para a ressonância destas idéias.

\section{A fantasia e a sedução}

Fantasia é Obra da imaginação, diz o Aurélio. Fantasiar seria criar, imaginar, idealizar. Uma relação já se percebe aqui entre fantasiar e idealizar. Como a fantasia é sempre maior que a realidade, idealizamos, quase sempre, para além de nossas possibilidades. Fantasiamos sobre 
aquilo que gostamos, que idealizamos e que nos falta. Fantasiamos sobre aquilo que gostaríamos de que o outro adivinhasse para nós. Fantasiamos o que vai mais fundo em nós, talvez o mais guardado, o mais proibido, o mais desejável, o não dito, o inacessível. A fantasia dizem quebra a rotina, ou seja, tira-nos do lugar comum, quem sabe? Conduz-nos a outras dimensões da vivência habitual. É como se o princípio do prazer fizesse um pacto com o princípio da realidade e dissesse: Com licença, eu vou sonhar. Aí se reconhecem não só os limites da realidade, mas também a concessão desta ao universo do desejo. A fantasia vem dizer que desejar não é proibido; pelo contrário, trata-se de lei universal. Contudo, fantasiar pode induzir a vôos para além do concebível à primeira vista. Há fantasias simples, sutis e outras muito profundas. Com relação à da mulher, Juan Nasio (1997, p. 189) comenta: Na fantasia da mulher, o objeto mais precioso, o falo, é o amor que vem do amado, e não o próprio amado. Assim, a angústia especificamente feminina é o medo de perder o amor e verse abandonada.

Um princípio de incerteza perpassa, assim, a sexualidade, a sedução, a fantasia, o erótico. Fantasia e sedução não são da ordem da natureza, mas do artifício, do signo e do ritual. As ações muito concretas no terreno do sexual se distanciam da fantasia e da sedução, porque certo afastamento se faz necessário nesses jogos. No jogo da sedução, a atração se exerce, curiosamente, por certo afastamento não se seduz o que já está à mão. A propósito, o termo sedução provém de se-ducere, que significa afastar, desviar de seu caminho desvio do real do corpo para dimensão mais próxima da fantasia. Há uma soberania da sedução, que é paixão, jogo, estratégia de deslocamento.

A sedução pertence à ordem do artifício, do signo, do ritual, e os discursos ou mostras excessivas constituem aí um desperdício. Começamos a seduzir quando o outro se põe como nosso objeto de desejo, mas por vias indiretas, que lhe escapam. É nessa escapada que o jogo seduz. O que é despertado pela sedução, pelo palco onde ela é encenada, é a fantasia, diz Sibony (1991, p. 30). Segundo ele, a trajetória, toda perpassada pela incerteza, envolve “[...] um jogo entre dois inconscientes, quando dois discursos, enrolados um no outro e presos na espiral que os ultrapassa, encontram-se no lugar comum de sua inconsciência (idem p. 27)".

Na sedução, não há anatomia, e sim ritual; seu papel é encantar a experiência natural vivida no real do corpo. Seduzir chega ao limite do ritual, onde os atores parecem não ter nada a ver com aquilo. Aí, desliza-se naturalmente da sedução para a fantasia. 
Baudrillard também fala da sedução como uma espécie de inteligência, como uma fulgurante evidência:

[...] não tem de se demonstrar, não tem em que se fundar está imediatamente ali, no avesso de qualquer pretensa profundidade do real, de qualquer psicologia, de qualquer anatomia, de qualquer verdade, de qualquer poder. Ela sabe é seu segredo que não há anatomia, que não há psicologia, que todos os signos são reversíveis. (BAUDRILLARD, 1992, p. 15)

Ela não se prende a nenhum território do saber convencional e difere do sexo, que é uma função: A sedução é da ordem do ritual, o sexo e o desejo são da ordem do natural (BAUDRILLARD, 1992, p. 27). Nesse ritual, amar desafia o outro a amar de volta. Tudo funciona secretamente no ato sedutor: "[...] eu sei o segredo do outro, mas não digo, e ele sabe que eu sei, mas não levanta o véu; a intensidade entre os dois nada mais é que o segredo do segredo" (idem 1992 p. 90). A sedução ganha a forma de um enigma a resolver: "[...] $a$ moça é um enigma e, para seduzi-la, é preciso tornar-se um outro enigma para ela; é um duelo enigmático, e a sedução é sua resolução sem que o segredo seja revelado. Descoberto o segredo, sua revelação seria a sexualidade."

Contudo, é possível a morte da sedução sob a obrigação de circulação do sexo, do valor mercantil dos corpos. Em qualquer lugar onde o sexo se erige em função, em instância autônoma, liquida-se a sedução (BAUDRILLARD, 1992, p. 49). Aí ganha força a economia do sexo lugar, talvez, de seu desencantamento. Na contraface das intensidades, Baudrillard (1992, p. 47) denuncia:

[...] Somos a cultura da ejaculação precoce. Cada vez mais, qualquer sedução, qualquer forma de sedução, que é um processo altamente ritualizado, apaga- se por trás do imperativo sexual naturalizado, por trás da realização imediata e imperativa de um desejo.

Na nossa cultura, o sexual triunfou sobre a sedução e anexou-a como forma subalterna, mas, na ordem simbólica, a sedução está lá primeiro, o sexo ocorre por acréscimo. A sedução tem a força de um enigma a resolver um duelo enigmático. Sua revelação seria a sexualidade.

\section{Desejo sexual. "O que será que será?"}

[...], pois desde que te vejo por um instante, não me é mais possível articular uma palavra: mas minha língua se quebra e um fogo sutil desliza de repente sob a minha pele: meus olhos não têm olhar, meus ouvidos zumbem, o suor escorre pelo meu corpo, um arrepio toma conta de mim; fico mais verde do que o capim, e por pouco me sinto morrer. (SAFO apud BARTHES, 1989, p. 136)

Da Psicanálise à Literatura ou à Poética, tem-se mostrado o desejo como uma espécie de 
hemorragia inestancável: Eis o cansaço amoroso: uma fonte que não é saciada, um amor escancarado (BARTHES, 1989, p. 137). Essa fome insaciável, esse cansaço que não quer descanso, essa busca infindável é o desejo algo que não se satisfaz completamente e retorna sempre em sucessivas buscas tal qual canta Chico Buarque:

Que é feito uma aguardente que não sacia / Que é feito estar doente de uma folia Que nem dez mandamentos vão conciliar / Nem todos os ungüentos vão aliviar [...].

Esse desejo insaciável é desejo de quê? Tentando responde àquestão, Garcia Roza (1991, p. 190) oferece a seguinte compreensão: “O que o desejo humano deseja é possuir o desejo do outro, é ser desejado ou amado pelo outro, é ser reconhecido em seu valor humano." Nossa agonia reside no fato de que não temos nenhum poder sobre o desejo do outro: ele nos deseja se o quiser; não lhe podemos impor isso por mais que o desejemos. Pode-se, sim, seduzi-lo, convocá-lo a amar de volta. A ânsia que não sossega, a agonia que nos possui é, no fundo, a ânsia de capturar o desejo do outro, a vontade profunda de que o outro nos deseje. Nada nos acalma tanto quanto a percepção, a certeza de sermos desejados pelo outro. Contudo, embora busquemos objetos capazes de atender provisoriamente ao desejo, não queremos que este silencie; queremos, na verdade, permanecer desejando.

Convivemos hoje com a deslocalização do desejo. A sexualidade liberada vem sendo vivida sob a forma de consumo, como se fosse mercadoria. De um lado, o sexo torna-se mercadoria; do outro, o comércio erotiza a mercadoria. A liberação sexual tem servido, de certo modo, a uma forma de adaptação ao grande mercado. Observemos a crítica de Guillebaud (1999, p. 110). Ela ganha terreno mais facilmente, à medida em que a própria linguagem erótica vai se vendo contaminada por um léxico de origem econômica: performance, concorrência, consumo, avaliação comparativa, predominância de curto prazo. Tal deslocalização para o mercado de consumo mina as possibilidades desejantes e amorosas. A perspectiva gradualmente se sedimenta em torno da sexualidade e do prazer funcionais e obrigatórios, como se isso garantisse a felicidade do sujeito sexual. A obrigação do prazer, do desempenho certeiro passou a integrar os requisitos de boa reputação.

Verdadeira cambalhota simbólica realizou-se em três décadas. Deslizamos "[...] da liberação à imposição, da permissividade conquistada à fruição obrigatória, da proibição à corvéia [...]" diz Guillebaud (1999, p.124). O dever do prazer não se torna aí uma nova forma de coerção? A onipresença do sexo na vida social, no discurso público, na mídia, não está 
também promovendo sua desvalorização? Um temor legítimo que perpassa a escrita de estudiosos é o de se promover com isso um esvaziamento do próprio desejo. Cresce, em nossos consultórios, a queixa da falta de interesse sexual. Que paradoxo: em tempos de tanta exaltação do sexo, tanta queixa de falta de desejo! Nossas sociedades tão agressivamente erotizadas, estão, na realidade, assaltadas pela ansiedade do não-desejo, explica Guillebaud (1999, p.130). A recomendação contemporânea tem sido um alerta para cuidarmos das fantasias como se cuida de um capital imaginário a ser preservado. Hoje não se luta mais contra a repressão do desejo, e sim contra sua falência.

\section{Reflexos sobre a vida sexual}

Destituída da erótica, da fantasia e da sedução, a vida sexual levaria as pessoas a "fazer sexo" mais do que "viver a sexualidade". Isso parece proceder da idéia de que ter muitas relações sexuais é um paradigma de normalidade, independentemente da qualidade de tais relações. Importa saber e fazer os outros saberem que se mantêm muitas relações sexuais atitude triunfal ante o sexo, como se este fosse um troféu que deve ser exibido. Bauman (2004, p. 13) critica a má qualidade daí proveniente: "Quando se é traído pela qualidade, tende-se a buscar desforra na quantidade". Nesses casos, a salvação estaria na velocidade com que se buscam, se usam e se descartam as relações, característica bem clara nos dias atuais. Com freqüência, clientes chegam perturbados por manterem pequeno número de relações sexuais. Poucos questionam, porém, a qualidade delas. Então buscam técnicas e remédios que atuem rápido e lhes garantam excitação, disposição, segurança, prazer e um número desejável de relações. Profunda inquietação os sufoca muitas vezes, nessa ânsia de verem-se normais sexualmente, mais do que saberem-se felizes sexualmente. O erotismo sucumbe a essa imposição do desempenho. Curiosamente o desempenho pode acontecer naturalmente, se o erótico se fizer presente na relação. O fazer sexual de forma empobrecida ofusca o viver sexual e faz da relação apenas lugar de comprovação de desempenhos. Vigilante de sua performance, o indivíduo pouco se entregará às sensações, ao prazer, ao encontro com o outro.

A ânsia de fazer sexo leva a pessoa a distanciar-se da sedução. Sem fantasia, sem sedução, a relação fica pobre, desprazerosa, talvez insustentável. O importante não é tanto que uma mão nos acaricie, mas saber a quem pertence essa mão, o que deseja essa pessoa e o que sentimos por ela, adverte Dorais (1994, p. 31). Há um sentido que permeia o tocar e trocar com o outro as emoções promovidas pelo sexo. A tonalidade encantada torna especial a relação e beneficia o desempenho. O desejo esse movimento encantado de captação do outro como parceiro de satisfação prazerosa fica ameaçado quando a preocupação maior se encontra em manter um nível de atuação sexual mais marcado pelo fazer e o quanto fazer. 
Um princípio de incerteza perpassa a erótica, a fantasia, a sedução, o desejo. Mas crescemos na rigidez da busca da certeza, do indubitável sobre o sexo. Será o homem contemporâneo capaz de tolerar a incerteza e dela fazer uma arte, um enigma sempre a resolver, um passo de dança, de modo que a sexualidade se torne tarefa excitante, incansável a ser inventada sempre, recomeçada sem perspectiva de silenciar-se ou deter-se? Por aí, não buscaremos a sexualidade arrebatadora, mas abriremos caminhos para sua vivência mais satisfatória, menos disfuncional.

\section{Referências bibliográficas}

BARTHES, R. Fragmentos de um Discurso Amoroso. Rio de Janeiro: Ed. Francisco Alves, 1998.

BATAILLE, G. O Erotismo. Porto Alegre: LP\&M, 1987.

BAUDRILlARD, J. Da Sedução. Campinas: Papirus, 1992.

BAUMAN, Z. Amor Líquido. Sobre a Fragilidade dos Laços Humanos. Rio de Janeiro: Jorge Zahar, 2004.

CHALHUB, A. Poética do Erótico. São Paulo: Ed. Escuta, 1993.

DORAIS, M. O Erotismo Masculino. São Paulo: Loyola 1994.

GARCIA ROZA, L. A. Metapsicologia Freudiana. 2. ed. Rio de Janeiro: Jorge Zahar, 1991.

GUILleBAUD. J. C. A Tirania do Prazer. Rio Janeiro: Bertrand Brasil,1999.

MÉNARD, R. Mitologia Greco-romana. São Paulo: Opus Editora, 1991.

NASIO, J. O livro da Dor e do Amor. Rio de Janeiro: Jorge Zahar, 1997.

PAES, J. P. Poesia Erótica em tradução. São Paulo: Cia das Letras, 1990.

PAZ, O. A Dupla Chama. Amor e Erotismo. São Paulo: Ed. Siciliano, 1994.

PRADO, A. Poesia Reunida. São Paulo: Ed. Arx, 1991.

ROZA. L. A. G. Introdução à Metapsicologia Freudiana. 2. Rio de Janeiro: Jorge Zahar, 1991.

SIBONY. D. Sedução. O Amor Inconsciente. São Paulo: Brasiliense, 1991.

STOLLER, R. Observando a Imaginação Erótica. Rio de Janeiro: Imago, 1998. 